\title{
Endoscopic ultrasound fine-needle aspiration vs. fine-needle biopsy: tissue is always the issue
}

Authors

Institutions
Eduardo Rodrigues-Pinto ${ }^{1,2}$, lan S. Grimm², Todd H. Baron ${ }^{2}$

${ }^{1}$ Gastroenterology Department, Centro Hospitalar São João, Porto, Portugal

${ }^{2}$ Division of Gastroenterology and Hepatology, University of North Carolina, Chapel Hill, North Carolina, USA submitted

22. November 2015

accepted after revision

30. November 2015

\section{Bibliography}

DOI http://dx.doi.org/

10.1055/s-0041-110952

Endoscopy International Open 2016; 04: E506-E507

(c) Georg Thieme Verlag KG

Stuttgart · New York

E-ISSN 2196-9736

\section{Corresponding author}

\section{Todd Huntley Baron, MD}

Division of Gastroenterology and Hepatology

University of North Carolina

School of Medicine

101 Manning Drive

Chapel Hill, North Carolina

27514

USA

Fax: +1-984-974-0744

todd_baron@med.unc.edu
Initially described by Vilmann et al. in 1992 [1], endoscopic ultrasound-guided fine-needle aspiration (EUS-FNA) is a validated diagnostic procedure in the field of gastrointestinal pathology. It is the current standard of care for sampling pancreatic mass lesions, with reported sensitivities ranging from $64 \%$ to $95 \%$, specificities from $75 \%$ to $100 \%$, and diagnostic accuracies from $78 \%$ to $95 \%$ [2]. However, the actual efficacy of EUS-FNA in practice depends on the site, size, and characteristics of the target tissue [3], as well as the availability of a cytopathologist to render an onsite diagnosis [4]. In order to overcome some of the limitations of FNA, needles designed to obtain biopsy specimens (fine-needle biopsy [FNB] needles) have been developed that allow core samples to be collected by shearing tissue from the target lesion. The expectation is that cutting needles will improve diagnostic accuracy as well as provide tissue with conserved architecture, enabling histological analysis [5].

The available literature comparing FNA and FNB needles has not provided definitive results $[6,7]$. A recent meta-analysis found no significant difference between one biopsy needle (ProCore; Cook Endoscopy, Bloomington, Indiana, USA) and standard FNA needles with regard to sample adequacy, diagnostic accuracy, or acquisition of a core specimen; however, the FNB needle established a diagnosis with fewer passes [8]. In this issue of Endoscopy International Open, Aadam et al. [9] present compelling data showing significantly higher rates of diagnostic yield and specimen adequacy for solid mass lesions sampled by FNB than for those sampled by FNA for all specimens. Although the difference in diagnostic yield was not statistically significant for pancreatic lesions, one could argue that it was clinically significant, at $91.7 \%$ compared with $78.4 \%$. A maximum of three passes was allowed for the first method of EUS tissue acquisition, and then patients were crossed over to the other type of needle based on on-site specimen adequacy. The differences were independent of lesion size, number of passes, use of suction or stylet, and needle gauge. The authors concluded that FNB should also be favored over FNA as a salvage technique when inadequate samples are obtained with FNA.

Analysis of cost-effectiveness from the perspective of a third-party payer (not representative of the methodology used in the randomized, controlled trial with crossover design) showed that FNB was more cost-effective than FNA for both pancreatic and nonpancreatic masses. This analysis included the use of on-site pathology for all examinations.

The lack of standardization of needle sizes is one weakness in the study design. Another concern is that the analysis of the crossover salvage effect may have been limited by the restricted number of passes that could be made with the initial needle. Previous experience with brush cytology for the diagnosis of biliary strictures and the potential role of dilation before or after sampling demonstrated that the increased sensitivity observed following stricture dilation was most likely a consequence of the act of obtaining additional samples [10].

As the authors recognize, there are significant cost implications associated with choice of needle and diagnostic strategy. If the routine use of FNB needles could provide diagnostic yields high enough to eliminate the need for on-site cytopathological evaluation, then there would be not only a reduction in direct costs but also a significant reduction in opportunity costs (costs associated with lost time pending cytological interpretation feedback). In fact, costs associated with downtime could ultimately prove to be the dominant driver in decision analysis. Total procedural time might be cut in half by performing FNB without on-site evaluation, potentially reducing hospital and anesthesia charges as well. The use of FNB as a salvage technique following unsuccessful 
FNA may not be cost-saving because this strategy requires two needles and extra time for additional passes; FNB alone may well be the dominant strategy for nonpancreatic lesions. However, if an FNB-alone strategy is used, it is imperative to determine the optimal number of passes and the needle gauge required to obtain a reliable diagnosis and exclude malignancy, and whether these variables differ by target organ. In theory, in the acquisition of a tissue core, EUS-FNB should be superior to FNA if needle design can be perfected. The day may soon come when EUS-FNB is analogous to tissue acquisition for mucosal lesions, in which samples are reliably obtained without the need for an onsite cytopathologist. Assuming that biopsy specimens are obtained from the lesion of interest and sampling is adequate, we might expect high diagnostic yields.

Four strategies are now available for obtaining tissue during EUS: FNA, FNB, both, and FNA with salvage FNB if the FNA samples are nondiagnostic. Ideally, a prospective blinded study should be conducted in which FNA and FNB are performed at the same site during the same endoscopic session with needles of matching gauges, similar to the one performed by Lin et al. [11], so that the diagnostic yields of EUS-FNA with on-site cytopathology and EUS-FNB without on-site pathology can be compared. Nevertheless, the current study by Aadam et al. is a significant step in the evolution of FNB, which may ultimately become the preferred method for EUS-guided tissue acquisition.

Competing interests: Dr. Baron is a speaker and consultant for $\mathrm{BSCl}$ and Cook Endoscopy. Dr. Grimm is a consultant for BSCI.

\section{References}

1 Vilmann P, Jacobsen GK, Henriksen FW et al. Endoscopic ultrasonography with guided fine needle aspiration biopsy in pancreatic disease. Gastrointest Endosc 1992; 38: 172 - 173

2 Itoi T, Sofuni A, Itokawa $F$ et al. Current status of diagnostic endoscopic ultrasonography in the evaluation of pancreatic mass lesions. Dig Endosc 2011; 23: 0117-21

3 Ieni A, Todaro P, Crino SF et al. Endoscopic ultrasound-guided fine-needle aspiration cytology in pancreaticobiliary carcinomas: diagnostic efficacy of cell-block immunocytochemistry. Hepatobiliary Pancreat Dis Int 2015; 14: 305-312

4 Song TJ, Kim JH, Lee SS et al. The prospective randomized, controlled trial of endoscopic ultrasound-guided fine-needle aspiration using 22G and 19G aspiration needles for solid pancreatic or peripancreatic masses. Am J Gastroenterol 2010; 105: 1739-1745

5 Levy MJ, Wiersema MJ. EUS-guided Trucut biopsy. Gastrointest Endosc 2005; 62: 417-426

6 Vanbiervliet G, Napoléon B, Saint Paul MC et al. Core needle versus standard needle for endoscopic ultrasound-guided biopsy of solid pancreatic masses: a randomized crossover study. Endoscopy 2014; 46: $1063-1070$

7 Strand DS, Jeffus SK, Sauer BG et al. EUS-guided 22-gauge fine-needle aspiration versus core biopsy needle in the evaluation of solid pancreatic neoplasms. Diagn Cytopathol 2014; 42: 751 - 7588

8 Bang JY, Hawes R, Varadarajulu S. A meta-analysis comparing ProCore and standard fine-needle aspiration needles for endoscopic ultrasound-guided tissue acquisition. Endoscopy (Epub 2015 Nov 12)

9 Aadam AA, Wani S, Amick A et al. A randomized controlled cross-over trial and cost analysis comparing endoscopic ultrasound fine needle aspiration and fine needle biopsy. Endosc Int Open 2016; 4: E497E505

10 de Bellis M, Fogel EL, Sherman S et al. Influence of stricture dilation and repeat brushing on the cancer detection rate of brush cytology in the evaluation of malignant biliary obstruction. Gastrointest Endosc 2003; 58: $176-182$

11 Lin M, Hair CD, Green LK et al. Endoscopic ultrasound-guided fine-needle aspiration with on-site cytopathology versus core biopsy: a comparison of both techniques performed at the same endoscopic session. Endosc Int Open 2014; 2: E220-E223 